Motrivivência Ano XXI, No 32/33, P. 193-210 Jun-Dez./2009

\title{
DESAFIOS DO JORNALISMO NA ERA DOS MEGAEVENTOS ESPORTIVOS
}

Anderson Gurgel

\begin{abstract}
Resumo Abstract
Neste artigo, fazemos um resgate dos conceitos e histórico do jornalismo esportivo para, num segundo momento, propor uma reflexão sobre as práticas jornalísticas no mundo do esporte. A visão que norteia este texto é a de que

o jornalismo esportivo já não cabe dentro dos seus próprios parâmetros tradicionais de conceituação, técnicas

e visão de objeto de cobertura noticiosa. O cenário que descrevemos é motivado pela complexa teia onde o jornalismo esportivo se insere, dentro das relações entre a comunicação e o esporte, mediados pelo espetáculo e o entretenimento. Acentua ainda
\end{abstract}

1 Anderson Gurgel, jornalista, professor mestre, é doutorando em Comunicação e Semiótica pela PUC-SP onde estuda a economia da imagem do esporte, sob orientação do Prof. Dr. Norval Baitello Junior. Ainda coordena os cursos de Jornalismo e Rádio \& TV da Universidade de Santo Amaro (Unisa) e pesquisa a interface da comunicação com o esporte e a economia e é autor do livro "Futebol S/A: A Economia em Campo", lançado em 2006 pela editora Saraiva. E-mail: andersongurgel@uol.com.br 
mais essa complexidade o fato de que um novo desafio impõe-se a toda a sociedade brasileira e ao jornalismo, em particular, com a realização dos megaeventos esportivos no Brasil, sendo os principais dele a Copa do Mundo de Futebol de 2014 e os Jogos Olímpicos Rio 2016. Palavras-chave: Jornalismo Esportivo; Megaeventos Esportivos; Cobertura Jornalística; Espetáculo; Economia do Esporte.

\section{Tradição e ruptura}

Neste artigo, o desafio que perseguimos é o de propor uma reflexão sobre o jornalismo esportivo dentro do atual cenário dos megaeventos esportivos e da expansão do entretenimento na mídia. Como pressuposto, adiantamos que o jornalismo esportivo já não cabe dentro dos seus próprios parâmetros tradicionais de conceituação, técnica e objeto de cobertura noticiosa. $\mathrm{O}$ enraizamento do esporte no mundo do entretenimento midiático, a espetacularização e o consumo no mundo desportivo e a atuação dos meios de comunicação de massa nesse cenário, ao longo do Século $\mathrm{XX}$, consolidaram o esporte, para além das suas fronteiras naturais, como agente econômico e político.

O caso torna-se ainda mais crítico, no cenário brasileiro, ao se levar em conta os desafios que estão entertainment. Further underlines this complexity the fact that imposes a new challenge to all of Brazilian society and journalism in particular with the achievement of sporting mega events in Brazil, the main goals of the World Cup Soccer 2014 and the Olympic Games 2016.

Keywords: Sports Journalism, Sports mega-events; Journalistic Coverage, Entertainment, Economics of Sports.

agendados com a realização da Copa do Mundo de Futebol de 2014 e dos Jogos Olímpicos Rio 2016. A partir desses megaeventos, o esporte coloca-se como item fundamental na agenda dos grandes interesses nacionais. É um enorme desafio para a cobertura jornalística desportiva dar conta dessa complexidade.

Ao iniciar a discussão, pontuamos que o jornalismo esportivo, na definição tradicional, apresentada pelo Dicionário Enciclopédico Tubino do Esporte (2007:719),

"é uma atividade especializada de Jornalismo na qual são transmitidas informações, opiniões (interpretações e críticas) e análises do esporte em qualquer aspecto de sua abrangência sociocultural. O jornalismo esportivo é exercido por jornalistas com conhecimento em esportes em 
Ano XXI, n 32/33, junho e dezembro/2009

geral ou em aspectos esportivo. (...) A cobertura jornalística esportiva, na sua maioria, é setorizada, podendo incidir sobre clubes, modalidades, entidades dirigentes ou outros aspectos esportivos importantes."

Como podemos perceber, essa conceituação é bastante tradicional e até utópica, no entendimento do que é jornalismo esportivo e sobre a prática da profissão. Mas o próprio dicionário (ibidem: 719) já aprofundando e atualizando a questão pontua que

“o jornalismo esportivo, cada vez mais, tem buscado o sentido do espetáculo, o que leva a uma identificação integrada com o show, o profissionalismo e o negócio. A criação, a difusão e o reconhecimento de ídolos e mitos no Esporte têm sido algumas das iniciativas do Jornalismo Esportivo na construção do espetáculo."

Já há literatura mais recente sobre o assunto que apresenta uma abordagem mais ampla, que traz uma ruptura e uma atualização do entendimento sobre o "fazer jornalismo esportivo". Joana Carvalho (apud PENA, 2005: 81), por exemplo, comenta:
“O jornalismo esportivo é o responsável por divulgar tudo o que acontece em relação ao esporte. O que vai desde o conceito de esporte como ferramenta de inclusão social até os noticiários especializados em modalidades esportivas de alto rendimento, onde estão condicionados aspectos como entretenimento e profissionalismo. Todo assunto de interesse da sociedade que envolva esporte é objeto do jornalismo esportivo."

A citação da pesquisa de Carvalho, apesar de aparentemente concordar com o que está no Tubino do Esporte, apresenta um problema: na prática do dia-a-dia dos grandes veículos de comunicação, o jornalismo esportivo acaba não dando conta da "sua real dimensão" na sociedade atual, ficando mais centrado nos aspectos ligados ao esporte de alto rendimento. Há muito pouco do esporte amador, das políticas públicas e privadas no âmbito esportivo, da promoção do esporte como fator de qualidade de vida, do impacto cultural do esporte na sociedade, entre outros fatores, na cobertura jornalística diária do esporte.

No nosso entendimento, a questão está longe de ser simples. O problema está muito além dos aspectos formais e técnicos e envolve também a questão das 
estratégias editorias dos veículos de comunicação de massa. Vejamos que Barbeiro e Rangel (2006:13) ponderam que

"Jornalismo é jornalismo, seja ele esportivo, político, econômico, social. Pode ser propagado em televisão, rádio, jornal, revista ou internet. Não importa. A essência não muda porque sua natureza é única e está intimamente ligada às regras da ética e ao interesse público."

Apesar de chamar a atenção para o fato de que o jornalismo focado no mundo esportivo ter que seguir os dogmas da prática jornalística, Barbeiro e Rangel não negam que a cobertura do jornalismo esportivo tem sim suas especificidades e, daí que eles alertam que (ibidem: 13):

"ele (o jornalismo esportivo) se confunde, freqüentemente, com puro entretenimento. Isto, por seu lado, propicia o aparecimento de alguns poucos 'coroados' e o envolvimento com outras atividades incompatíveis com a prática do jornalismo, como agenciamento de publicidade, marketing e política privada dos clubes, federações, confederações e empresas."
O nó teórico-prático sobre o "fazer jornalismo esportivo" dá-se justamente na fronteira do esporte espetáculo e agente do consumo versus esporte amador para a prática lúdica e descompromissa; do jornalismo do entretenimento espetacular versus o jornalismo que promove as práticas culturais em prol de uma sociedade melhor (incluindo-se o esporte nelas) versus o jornalismo que "propagandeia" celebridades e produtos na indústria cultural.

Carvalho (apud PENA, ibidem: 81), relativizando sobre as características desse tipo de prática jornalística, pondera que

"a característica fundamental do jornalismo esportivo, e que diferencia essa editoria de qualquer outra, é a paixão que o esporte desperta no público. Ao produzir seu texto para jornal, rádio ou internet, o jornalista esportivo tem que estar ciente de que está lidando com uma paixão do leitor/espectador. E por conta disso, a editoria de esporte é a que consegue atingir todas as classes sociais."

De certa forma, os aspectos passionais que envolvem o esporte são um fator preponderante. Se por um lado permite humanizar a prática jornalística, por outro lado pode ser ferramenta de manipulações e inte- 
Ano XXI, n 32/33, junho e dezembro/2009

ressantes político-econômicos diluídos em uma singela embalagem de "paixão esportiva". A partir de tudo o que foi exposto até aqui, vamos agora fazer uma breve explanação sobre a evolução do jornalismo esportivo, também item fundamental, para o que pretendemos desenvolver neste artigo.

\section{Parceria histórica}

Ao fazer uma breve explanação sobre a evolução do jornalismo esportivo, cabe frisar que há uma boa literatura sobre isso. Destacamos inclusive o trabalho de Ribeiro (2007), ao falar detalhadamente da história da imprensa esportiva no Brasil. Sobre a evolução da imprensa, no diálogo com os negócios do esporte, recomendamos GURGEL (2006). Dentro do objetivo que pretendemos aqui, vamos somente trazer alguns elementos cruciais que nos permitam discutir a necessidade de se repensar o jornalismo esportivo. Para ter uma conceituação mínima, seguiremos a visão do Dicionário Tubino do Esporte (ibidem: 718-721).

O jornalismo esportivo começou na Europa quando, em 1852, na Inglaterra, foi publicado o Sportman, o primeiro diário esportivo. Longe de ser um fato isolado, no mesmo período, as pesquisas apontam que, em outros países europeus, várias publicações esportivas estavam sendo criadas. No começo, não havia práticas esportivas majoritárias , como o futebol, o que permitia uma percepção do esporte num sentido mais social e de saúde. Para o Tubino do Esporte (idem: 719), o primeiro jornal da América nessa área foi a publicação Atleta, de 1856, "que apresentava ensinamentos para o aprimoramento físico dos habitantes da cidade do Rio de Janeiro".

Um dos jornais mais antigos do mundo, o Gazzetta Dello Sport, criado em Milão, na Itália, é de 1896, mais precisamente data do início dos primeiros Jogos Olímpicos da Era Moderna, disputados em Atenas. Nos primórdios, as publicações apresentavam textos variados, falando de práticas de atividade física, do turfe, do ciclismo, do remo, do boxe e muitos outros.

Com o surgimento do rádio novas fronteiras se abrem para a promoção do esporte. Uma experiência importante no aperfeiçoamento da mídia esportiva foi a primeira transmissão, em 1921, de uma luta de boxe, nos Estados Unidos, envolvendo os lutadores pesos-pesados Jack Dempsey e Joe Carpentier. "A transmissão foi da Rádio KDK e marcou também a ascensão do rádio como importante meio de comunicação de massa" (ibidem: 719). 
Sobre a ascensão do futebol como paixão nacional e também na sua relação com a mídia indicamos a leitura do livro O Negro no Futebol Brasileiro (MÁRIO FILHO, 2003). Mas em linhas gerais, ainda na década de 1920, o futebol como a ganhar destaque no noticiário esportivo tanto na Europa quanto na América do Sul. A década de 1930, que trouxe a profissionalização do futebol brasileiro, marca essa expansão de forma definitiva.

O Tubino do Esporte pontua que os jornais, por exemplo, começam a formar especializadas para cobrir o esporte, com destaque para a mudança na linguagem, com valorização de fotografias e opiniões. Essa mudança acelerada gerou um importante fenômeno (idem, ibidem: 719):

“... com o tempo, o noticiário se modificou de acordo com a preferência do público por determinados esportes. Cada lugar procurava valorizar modalidades específicas que passaram a fazer parte de um processo de identidade cultural. $\mathrm{O}$ esporte se tornou, com a força do jornalismo, um importante fenômeno de cultura e não apenas educacional, e passa a ser tratado na perspectiva do lazer e das competições, transmitidas como informação pelos veículos de comunicação."
Foi nesse contexto que o futebol, a partir da década de 1930 desponta como grande modalidade esportiva no Brasil, rompendo com seu passado elitizado e ganhando entre todas as classes sociais. O papel do rádio nesse processo é inquestionável, já que ele permitiu a uniformização da informação, em um país com alto nível de analfabetismo, a começar pela Rádio Nacional, do Rio de Janeiro, que levava a paixão pelos clubes cariocas aos mais profundos rincões do Brasil. Ainda hoje percebemos a marca dos meios de comunicação na propagação do futebol pelo país: o fato de clubes como Flamengo e Vasco da Gama ter projeção e torcida em âmbito nacional dialoga diretamente com as estratégias de veiculação dos jogos ainda na primeira metade do Século XX.

Apesar da força do rádio, importantes produtos impressos surgiram até meados do século passado. Um deles foi o Jornal dos Sports, do Rio de Janeiro, em 1931. Nesse veículo, também se destacou uma personalidade fundamental para o jornalismo esportivo brasileiro, o jornalista Mário Filho. Ele foi um importante criador de aspectos fundamentais das técnicas de cobertura jornalística do esporte, além de importante agente de mudanças no campo da profissionalização esportiva e da promoção da inserção do 
Ano XXI, n 32/33, junho e dezembro/2009

esporte social e economicamente na sociedade brasileira. Além disso, esse jornalista foi um grande promotor da paixão futebolística, o que culminou na realização em território nacional da Copa do Mundo de 1950 (GURGEL, 2006: 07-39).

Com o cinema, o esporte descobriu seu forte apelo visual e sua vocação para o espetáculo, trazendo para o grande público as imagens que eram imaginadas principalmente nas transmissões de rádio ou, ainda, na leitura de jornais e revistas, para os que sabiam ler. Um marco na expressividade do esporte no cinema é o documentário Olympia, da cineasta alemã Leni Riefenstahl. Nesse trabalho, a cineasta mistura técnicas de cobertura jornalística com elementos da estética clássica e a narratividade mítica para documentar os Jogos Olímpicos de Berlim, de 1936, no auge do Nazismo. A forma de ela mostrar o corpo do atleta e os atos dos atletas e impacto desses na plateia influencia as produções audiovisuais até hoje.

Contudo, foi a partir da ascensão da televisão que tudo muda na relação do jornalismo com o esporte e, até, na forma como os torcedores apreciam suas modalidades e times preferidos. Para o Tubino do Esporte, "a televisão modificou a comunicação e passou a valorizar o esporte como um espetáculo de imagens e informação" (ibidem: 720). É importante lembrar que ainda, do ponto de vista de massificação, o rádio ainda era fundamental, e essa relação somente começa a mudar na década de 1970. Ainda em 1936, por exemplo, a Rádio Nacional cria a primeira programação esportiva, o No Mundo da Bola, que tinha como anunciante a multinacional Sidney Ross.

Voltando à televisão, a primeira transmissão esportiva integral foi realizada em 1948 nos Jogos Olímpicos de Londres. De certa maneira, após a Segunda Guerra Mundial, a realização dos grandes eventos esportivos agenda a divulgação de novas e decisivas tecnologias de telecomunicações. A evolução tecnológica também permite a complexificação da rede criada nos meios de comunicação de massa amplificando o perder de influência do jornalismo no mundo esportivo. Como já citado, um caso célebre é o da Copa do Mundo de 1950, realizada no Brasil (ibidem: 720):

“O jornalista Mário Filho, por intermédio do Jornal dos Sports, desenvolveu uma campanha para o então governador do Rio de Janeiro construir um estádio na região da Tijuca, um bairro de melhor acesso para o público. Mário Filho Filho conseguiu a aprovação da construção do 
Maracanã, que passou a ser o maior estádio do mundo."

Recomendamos para um aprofundamento na evolução do jornalismo esportivo, os pesquisadores e autores aqui já citados. Para que consigamos dar conta do que se busca neste artigo, vamos agora dar alguns saltos históricos, lembrando, por exemplo, que a Revista Placar, da Editora Abril, foi criada em 1970. Com 40 anos de existência, apesar da circulação inconstante, a revista foi importante agente na consolidação do jornalismo esportivo na segunda metade do Século XX.

Data também do começo da década de 1970 a expansão da televisão no mundo esportivo, com maior tempo de dedicação e também ampliação da publicidade especializada. Surge na Rede Globo, nesse mesmo ano, o programa Esporte Espetacular. Como salienta Pozzi (1998: 106):

“Na verdade chegamos a um estágio tal que o esporte e a mídia são totalmente dependentes um do outro. De um lado, a mídia (especialmente a TV) foi a grande responsável pela popularização de inúmeras atividades esportivas. De outro, as transmissões esportivas rendem as maiores audiências que a TV pode obter, garantindo a satisfa- ção de telespectadores e anunciantes."

Reforçando os comentários de Pozzi, trazemos os de Murray (2000: 201-202), para quem um dos principais fatores da transformação do futebol em produto de consumo primordial é mesmo a televisão:

“Embora ela (a televisão) já integrasse a vida da maioria das pessoas do mundo desenvolvido desde 1960, os avanços tecnológicos e os modelos ideológicos dos anos 1980 tornaram-na um elemento inevitável da vida cotidiana, junto aos aparelhos de fax, telefones celulares, computadores pessoais e videogames. Apesar de não ter causado um impacto notável dentro de campo, revolucionou sua organização e modificou seu efeito sobre o público. Pela televisão, a arte dos grandes jogadores e $o$ desempenho dos grandes times podem ser acompanhados por milhões de pessoas, que antes só liam ou ouviam as notícias."

O Tubino do Esporte, em consonância, enfatiza que "as relações entre televisão e sua audiência começaram a se alterar na década de 1990, com o crescimento das emissoras por assinatura" (ibidem, 720). Com a criação desses veículos 
Ano XXI, n 32/33, junho e dezembro/2009

de comunicação, o esporte começa a ganhar cada vez mais tempo de exposição imagética e, com isso, maior público. Esse caminho histórico levou ao surgimento do sistema pay-per-view, no qual o telespectador compra o direito de assistir a um programa na sua casa e, no período mais recente, também ao surgimento de uma alteração nos papéis dos agentes produtores do espetáculo esportivo (entidades do esporte, clubes, etc.) com o dos agentes produtores da veiculação da informação jornalística do esporte²:

“Na Inglaterra, o Esporte passou a ser o principal produto para as emissoras por assinatura. (...) Essa iniciativa fez com que entidades gestoras passassem a regular a interligação de clubes com empresas de comunicação, além de promoção de parcerias com os principais grupos jornalísticos, a fim de prevenir possíveis conflitos de interesse e negociar os custos dos direitos de imagem" (ibidem, 721).

O Brasil tem suas particularidades na questão da ascensão da televisão como maior força do jornalismo esportivo e também como agente fundamental na promoção do esporte. Os canais de televisão por assinatura não são tão fortes quanto em outros países, mas pertencem a grupos de comunicação que são verdadeiros conglomerados de entretenimento que acabam tendo tanta força, como na Inglaterra, no exemplo acima.

Para encerrar esta breve explanação sobre a evolução das relações entre o jornalismo e o esporte, cabe pontuar as novas tecnologias e a expansão das mídias digitais, principalmente da cobertura jornalística online. Vejamos o que diz o sobre isso o Tubino do Esporte (ibidem, 721):

"A internet passou a ser a base da comunicação global mediada por computadores, constituindo em uma rede livre de informação. Muitos sites esportivos passaram a ser desenvolvidos em todo o mundo no fim da década de 1990 e início do ano 2000 por editoras, empresas jornalísticas e entidades de esporte. Os sites possibilitaram o acesso a dados estatísticos, tabelas, informe de eventos e históricos, complementando o noticiário dos jornais e revistas especializados. As grandes coberturas passaram a ter o suporte do tempo real".

2 Para os interessados, informamos que no livro Futebol S/A: A Economia em Campo (GURGEL, 2006) há uma profunda análise da expansão e dos problemas dessas relações. 
Colocamos o grifo na citação acima no ponto que nos parece equivocado sobre a internet ser "uma rede livre de informação", a partir da evolução da comunicação - e dentro dela do jornalismo esportivo - no início do Século XXI. Inegavelmente a internet revolucionou a forma de se fazer jornalismo, mas de alguma maneira foi incorporada também pelo jornalismo tradicional, já que os principais veículos de comunicação online pertencem a grandes conglomerados de mídia que integram suas plataformas de comunicação.

Os próprios direitos de transmissão dos grandes eventos esportivos são vendidos em contratos "casados" envolvendo direitos para televisão aberta, por assinatura e internet. Um bom exemplo disso, no Brasil, é a Rede Globo, com as transmissões esportivas na TV Globo, canal aberto, e na Sportv, por assinatura, e no GloboEsporte.com, dentro do Portal G1, na internet. Mas esse é justamente o ponto que discutiremos a seguir, para falar dos desafios e do jornalismo.

\section{Jornalismo esportivo revisi- tado}

Como já vimos anteriormente, os meios de comunicação de massa interferiram significativamente na construção do esporte espetáculo como conhecemos.
Após vermos uma breve evolução histórica dessa relação, cabe agora problematizar o cenário em que se insere o jornalismo esportivo atualmente. Uma boa forma de iniciar essa discussão é a partir da classificação dos principais períodos do jornalismo, criada por Marcondes Filho (2000). O pesquisador divide o jornalismo em cinco grandes fases, sendo a primeira delas a da pré-história dessa profissão, caracterizada pelo modelo de operação artesanal e conteúdo formado por um misto de literatura e notícia.

Já no Primeiro Jornalismo, logo após a Revolução Francesa, surge o modelo profissional, com a criação das redações e com a busca da razão e transparência como fundamentos. O Segundo e o Terceiro Jornalismo são marcados, respectivamente, pela imprensa calcada na sociedade de massa e pela formação de monopólios de comunicação (ibidem: 48). Esses dois momentos, também, são cruciais para o entendimento da expansão do esporte como objeto jornalístico e, na contrapartida, para o aumento da interdependência entre empresas de comunicação e instituições esportivas na sociedade moderna.

Por fim, acrescentamos que Marcondes Filho denomina a atual fase de Quarto Jornalismo. Mesmo trazendo características das fases anteriores, principalmente 
Ano XXI, n 32/33, junho e dezembro/2009

as duas últimas, ela é calcada nos avanços tecnológicos e na alteração das funções do jornalista, inclusive com a constatação de que "toda a sociedade passa a produzir informação" (ibidem: 48), visão que até já antecipa um pouco o que veio a se radicalizar com o surgimento das redes sociais.

O momento atual das mídias contempla também a busca incessante de velocidade, com a informatização e a virtualização do trabalho jornalístico. Há uma relação direta disso tudo com a sociedade do espetáculo, como conceituada por Debord (1997). Cabe pontuar que é comum a associação entre esporte e espetáculo, principalmente quando se fala de grandes eventos esportivos ou megaeventos esportivos, conceito usado para definir tais eventos atualmente . $^{3}$

Inferimos que há muito tempo as práticas esportivas tornaram-se um dos nichos de negócios mais rentáveis dentro da ascendente economia do entretenimento, e a espetacularização, como Debord (1997:13-25) deixa claro, representa um importante elemento desse processo:

"Toda vida das sociedades nas quais reinam as modernas condições de produção se apresenta como uma imensa acumulação de espetáculos. Tudo o que era diretamente vivido se afastou numa representação. (...) O espetáculo não é um conjunto de imagens, mas uma relação social entre pessoas, mediada por imagens. (...) O espetáculo é o capital a um tal grau de acumulação que se torna imagem".

O esporte como espetáculo gera um "show de imagens", que é ingrediente perfeito para o entretenimento na sociedade contemporânea. Jogos, jogadores, jogadas, façanhas e narrativas, arenas, torcedores, produtos, dirigentes, políticos, produtos e celebridades do (e no) esporte são alguns dos itens fundamentais dessa grande fonte geradora de imagens e imaginários que constroem um sistema de práticas e de sentido inseridos no ambiente capitalista do trabalho e da geração de interesses econômicos.

Quando se fala em espetáculo esportivo fala-se, por conseqüência, de um sistema de imagens geradas pelo e para o esporte e, mais especificamente, das imagens geradas pelas dinâmicas ligadas ao espetáculo midiatizado relacionado aos esportes. Os megaeventos esportivos - como os Jogos Olímpicos

3 Uma boa referência para o entendimento dessa questão é o livro Legado dos Megaeventos Esportivos (DaCOSTA et al., 2008). 
e as Copas do Mundo de Futebol, entre outros - adquirem papel estratégico, pois eles representam o ápice desse processo de construção de imagens esportivas espetaculares, que são midiatizadas de forma massiva. E são um grande desafio para o jornalismo esportivo.

Podemos afirmar que o esporte é ingrediente fundamental da indústria cultural do entretenimento nos meios de comunicação de massa contemporâneo, como Bourdieu (2007) expõe ao ilustrar o caso dos Jogos Olímpicos. O pensador francês vai além e aponta que o espetáculo criado, pelos meios de comunicação de massa - sendo o carro-chefe a televisão - "deve ser concebido de maneira a atingir e prender o mais duradouramente possível o público mais amplo possível" (idem:124). Dessa percepção, ele constata que o espetáculo das Olimpíadas e Copas do Mundo, entre outros megaeventos esportivos, é produzido de certa maneira duas vezes:

"uma primeira vez por todo um conjunto de agentes, atletas, treinadores, médicos, organizadores, juízes, cronometristas, encenadores de todo o cerimonial, que concorrem para o bom transcurso da competição esportiva no estádio; uma segunda vez por todos aqueles que produzem a reprodução em imagens e em discursos desse espetáculo, no mais das vezes sob a pressão da concorrência e de todo o sistema das pressões exercidas sobre eles pela rede de relações objetivas na qual estão inseridos (idem, 127)".

O problema que se coloca, quando se propõe a discutir o jornalismo esportivo, é justamente o enfraquecimento do jornalismo no embate com o espetacularização do esporte. Como já abordamos as emissoras de televisão, que fazem parte de grandes conglomerados de comunicação e entretenimento, assumiram a função expansionista e reguladora do esporte ${ }^{4}$. Para a discussão sobre que interesse a este artigo essa constatação revela alguns problemas: um dos problemas é a questão dos aspectos éticos envolvendo a cobertura jornalística, no caso das emissoras que são agentes da produção do espetáculo esportivo e, ao mesmo, atuam na sua cobertura jornalística. Outro ponto é que o poder da televisão enfraqueceu a mídia impressa no seu trabalho de cobertura dos eventos esportivos. É inegável que nos últimos anos, 
Ano XXI, n 32/33, junho e dezembro/2009

com a expansão da internet, esse cenário começa a mudar, mas o "big business" do esporte ainda está na cobertura televisiva.

Contudo, como pontua Dines (1996: 90) o jornalismo clássico "terá de engolir e aceitar a existência da TV como veículo noticioso e seu principal concorrente". O jornalista e pesquisador, quando afirmou isso ${ }^{5}$, ainda não contemplava a existência de mídias digitais, mas o princípio proposto de que o leitor dos impressos "não quer apenas saber o que acontece à sua volta, mas assegurar-se da sua situação dentro dos acontecimentos", continua atual e mais imperativo, no mundo das novas tecnologias e da internet. Sendo assim, ele ainda sugere uma "receita" para "o papel do jornal" à luz dos novos tempos:

"Isto (o asseguramento do leitor) só se consegue com a dimensão comparada, a remissão ao passado, a interligação com outros fatos, a incorporação do fato a uma tendência e a sua projeção para o futuro (idem, ibidem: 90)".

Ou seja, o jornalismo esportivo para sobreviver ao espetáculo - com a sua irresistível vocação para o marketing e a propaganda - terá de ser cada vez mais jornalismo, revendo seus conceitos de escopo de cobertura e interesse do público-alvo. Ressaltamos que se apresenta atualmente um contexto em que, as editorias clássicas do jornalismo, enquanto superfície de inscrição das "notícias mais importantes do dia" na sociedade, não dão mais conta da realidade. Os saberes antes facilmente classificáveis em editorias como Internacional, Cidades, Esportes, Economia entre outros ganham agora contornos mais complexos.

Tentando dar conta dessa diversidade, surgem cada vez mais espaços para suplementos e especiais no dia-a-dia das publicações. Alguns já se configuram como obrigatórios, outros se transformam em subeditorias e outros já aspiram à posição de editorias. No âmbito do esporte, por exemplo, temos a questão do marketing esportivo e os negócios do esporte, abordados com foco econômico. Ainda há questões do turismo esportivo, do entretenimento e da cultura do esporte, das novas tecnologias de/no esporte, da qualidade de vida e saúde, da educação e capacitação profissional de/no esporte, entre outros temas. $\mathrm{O}$ desafio de áreas que se consolidam

5 O livro O Papel do Jornal, um clássico do Jornalismo, foi escrito na década de 1970, quando da crise do petróleo e da ascensão da TV na sociedade brasileira. 
e que provocam uma reação do jornalismo, principalmente no campo do esporte, é o de como dar conta da imensa variedade de novas demandas da sociedade de consumo e sem perder a verdadeira vocação do jornalismo.

\section{CONSIDERAÇÕES FINAIS: pistas em uma trama complexa}

Anteriormente contextualizamos o jornalismo dentro da complexidade que se forma na expansão espetacular dos megaeventos. Não temos a ambição aqui de dar conta de todos os caminhos possíveis para responder a essa realidade. Nessas consideraçõs finais, pretendemos deixar algumas pistas sobre temas e estratégias que podem contribuir para uma melhor adequação da cobertura jornalística frente a esses novos cenários. O caminho que defendemos como uma forma de atualizar o jornalismo esportivo é o da ampliação da ênfase nos aspectos sócio-econômicos do esporte.

Mesmo que inicialmente soe como contraditório, o fato é que para se produzir um bom jornalismo esportivo, cada vez mais, é fundamental entender os aspectos sociais, politicos e fundamental- mente econômicos envolvidos no contexto da prática esportiva em observação jornalística. Vejamos um caso célebre onde esse entendimento pode lançar luz: Em 08 de março de 20092009, o jornalista e até então ombudsman da Folha de S.Paulo, Carlos Eduardo Lins e Silva, criticava na sua coluna que "Sobra espaço para Ronaldo; falta espaço para o resto em Esporte" ${ }^{\prime}$. Ele acrescenta:

“Ronaldo, 'o fenômeno', é um dos melhores jogadores de futebol da história, o maior artilheiro em Copas do Mundo. É justificável que os veículos de comunicação acompanhem seus passos, pelo interesse que desperta em milhões de pessoas. Mas desde que foi contratado pelo Corinthians, a Folha tem demonstrado obsessão por ele (...). Nos 84 dias entre a sua contratação e anteontem, o jornal publicou 70 fotos de Ronaldo. (...) O mais grave é que esse monte de espaço é gasto enquanto o caderno Esporte é cobrado por centenas de leitores que se queixam de mau atendimento de suas expectativas na cobertura de seus times de futebol (como a Portuguesa e os grandes de outros Es-

6 Para saber mais, veja Gurgel (2009), artigo feito para o XXXII Congresso Brasileiro da Intercom. 
Ano XXI, n 32/33, junho e dezembro/2009

tados) e de outras modalidades esportivas."

A crítica feita pelo Ombudsman da Folha de S.Paulo ao próprio jornal em que ele trabalhava na época pode ser vista como um bom exemplo dos impasses aqui em discussão. Não está em discussão a importância do jogador Ronaldo para o esporte, mas sim a dificuldade que o jornalismo esportivo está encontrando para equilibrar todos os interesses e temas pertinentes ao seu universo no universo do esporte espetáculo atual - isso sem falar que praticamente não há espaço para o esporte amador na cobertura dos veículos de comunicação de massa.

Por isso e, por fim, defendemos que o jornalismo esportivo precisa de uma revisão dos seus conceitos, para dar conta da complexidade que se apresenta. Além da inegável importância de se dialogar criticamente com o marketing esportivo em ascensão dentro do esporte brasileiro, a releitura do escopo da cobertura esportiva precisa atentar-ser para urgência no entendimento de novos conceitos como economia e legado do esporte.
Ao falar de economia do esporte, indicamos um trabalho de referência que é o de Heinemann (2001), que analisou o caso de Barcelona, pós-Olimpíadas, como um dos maiores exemplos de transformação urbana e social a partir dos impactos do esporte, é possível distinguir dois tipos de atividades esportivas relevantes economicamente: 1 . a prática esportiva da população com os seus interesses e efeitos econômicos e 2. um segundo grupo, que é o dos grandes eventos esportivos, que nos interessa mais diretamente aqui. Nos dois casos, são analisados valor econômico de oferta e demanda do mercado esportivo, balança comercial do esporte; o mercado de trabaIho relacionado à área e, por fim, os efeitos externos ou indiretos.

Já na questão do legado do esporte, dialogamos com os trabalhos de Preuss. Como revela Poynter, citando o pesquisador Preuss $^{7}$, em um estudo do London East Research Institute ${ }^{8}$, de março de 2006 (p.13-4), esse

'conceito de 'legado' decorren-
te de importantes megaeventos
esportivos está agora firmemente

7 Holger Preuss, professor da Universidade de Mainz, Alemanha, é uma das maiores autoridades do mundo em estudos sobre megaeventos e legado esportivo.

8 O artigo foi traduzido no Brasil no contexto de preparação para o Seminário sobre Megaeventos e Legados, realizado no Rio de Janeiro, em maio de 2008. Texto integral consultado em 30/05/2008. Veja material in: http://www.confef.org.br/arquivos/texto_introducao_seminario_megaeventos.pdf 
focado em resultados não-esportivos como importante fonte de legitimidade para receber os Jogos (...) as cidades proponentes têm aliado suas propostas a estratégias de desenvolvimento econômico e regeneração que tendem refletir a natureza relativamente dinâmica de suas economias regionais e nacionais (Seul, Beijing) ou a relativa falta de dinamismo de suas economias (Barcelona, Atlanta, Sydney, Atenas e Londres). Este último grupo composto na maioria por cidades "ocidentais" que utilizaram a candidatura como uma tentativa de 'catalisar' a regeneração local através da expansão de serviços com base em indústrias voltadas ao consumo (...) desde os Jogos Olímpicos de 1992 em Barcelona, cidades, têm usado os Jogos como catalisadores de regeneração e confiado fortemente em diferentes formas de intervenções estatais para se promoverem como cidades globais (...)".

É claro que entendemos que a problemática da renovação do jornalismo esportivo carece de outras reflexões. Mas enfatizamos que um dos pontos fundamentais é o entendimento de que não é possível mais acompanhar jornalisticamente o esporte alheio às questões dos negócios do esporte. Com o agendamento da Copa do Mundo de 2014 e dos Jogos Olímpicos Rio 2016 na "pauta nacional", o jornalismo esportivo está na berlinda. Ou rapidamente recicla-se para dar conta desse cenário altamente complexo para ser acompanhado e levado aos seus públicos ou perderá seu espaço para outros segmentos do jornalismo, como o econômico, que já entenderam que o esporte virou coisa "séria" e item obrigatório para o entendimento do Brasil das primeiras décadas do Século XXI.

Há uma "década de ouro" a ser confirmada nos próximos anos nas políticas esportivas e na possibilidade de fazer do esporte um elemento único na integração e no desenvolvimento nacional. É dever dos comunicadores sociais e das empresas onde eles trabalham se preparar para fazer seu papel. E isso não significa somente criticar problemas de gestão de recursos ou denunciar o descumprimento de prazos.

O bom jornalismo deve ser a ferramenta para a promoção da cidadania, para a criação de novas lideranças, para o estímulo ao surgimento de mecanismos sociais de controles de possíveis desvios de rota que possam surgir em projetos tão complexos como são os da Copa do Mundo e da Olimpíada brasileiras. Esse é o desafio para o jornalismo nos próximos anos: ajudar o 
Ano XXI, n 32/33, junho e dezembro/2009

Brasil a aproveitar a oportunidade histórica que se apresenta.

\section{REFERÊNCIAS}

BARBEIRO, H.; RANGEL, P. Manual do Jornalismo Esportivo. São Paulo: Editora Contexto, 2006.

BOURDIEU, P. Sobre a Televisão.

Rio de Janeiro: Jorge Zahar Editor, 1997.

DACOSTA, L.; CORRÊA, D.; RIZZUTI, E.; VILLANO, B. e MIRAGAYA, A. Legado dos Megaeventos Esportivos. Brasília: Ministério do Esporte, 2008.

DEBORD, G. A Sociedade do Espetáculo. Rio de Janeiro: Contraponto, 1997.

DINES, A. O Papel do Jornal - Uma releitura. São Paulo: Summus Editorial, 1986.

GURGEL, A. Futebol $S / A-A$ Economia em Campo. São Paulo: Editora Saraiva, 2006. . "Ronaldo em dois tempos no jogo econômico". In: XXXII Congresso Brasileiro de Ciências da Comunicação Intercom. GP Comunicação e Esporte. Curitiba, 2009.

HEINEMANN, K. "La Repercusión Económica del Deporte: Marco Teórico y Problemas Prácticos." In: Revista Digital EFDeportes, Ano 7, $n^{\circ}$ 43. Buenos Aires,
Dezembro de 2001. Na internet: http://www.efdeportes.com/ efd43/econom.htm

\section{- Introdución}

a la Economía del Deporte. Barcelona: Editorial Paidotribo, 1998.

MARCONDES FILHO, C. Comunicação e Jornalismo - A Saga dos Cães Perdidos. São Paulo: Hacker Editores, 2000. MARIO FILHO. O Negro no Futebol Brasileiro. $4^{\mathrm{a}}$ Edição. Rio de Janeiro: Editora Mauad, 2003.

MURRAY, B. Uma História do Futebol. São Paulo: Hedra, 2000.

PENA, F. Jornalismo. Coleção 1000 Perguntas. Rio de Janeiro: Editora Rio-Universidade Estácio de Sá, 2005.

POYNTER, G. "Estudos Urbanos - De Beijing a Bow Bells". Texto do London East Research Institute cedido ao Seminário de Megaeventos e Legado Rio de Janeiro, maio de 2008. In: Confederação Federal de Educação Física, 2006. Acessado dia 30/05/08, às 23h30.In: http:// www.confef.org.br/arquivos/ texto_introducao_seminario_ megaeventos.pdf.

POZZI, L. F. A Grande Jogada Teoria e Prática do Marketing Esportivo. São Paulo: Editora Globo, 1998. 
RIBEIRO, A. Os Donos do Espetáculo

- Histórias da Imprensa Esportiva no Brasil. São Paulo: Editora Terceiro Nome, 2007.

TUBINO, M. J. G.; TUBINO, F. M. e GARRIDO, F. A. C. G. Dicionário Enciclopédico Tubino do Esporte. Primeira Edição. RJ: Editora Senac, 2007.

Recebido: Junho/2010 Aprovado: Agosto/2010 